\title{
The role of small intestinal bacterial overgrowth in food intolerances
}

\author{
Marcelina Bartuzi', Natalia Ukleja-Sokołowska² \\ ${ }^{1}$ Students' Scientific Association of Allergology, Department of Allergology, Clinical Immunology and Internal \\ Diseases, Collegium Medicum in Bydgoszcz, Nicolaus Copernicus University in Toruń \\ 2 Department of Allergology, Clinical Immunology and Internal Diseases, Collegium Medicum in Bydgoszcz,
}

Nicolaus Copernicus University in Toruń

\begin{abstract}
:
Food intolerances are increasingly common in populations of developed countries. One of the important factors in the etiopathogenesis of this phenomenon is disorders of the bacterial composition of the human gastrointestinal tract. The development of civilization as well as the increasing production of processed food contribute to the increased incidence of diseases of the digestive system, such as small intestinal bacterial overgrowth and food intolerances. These conditions may occur separately or coexist in one patient. The incidence of food intolerances and also allergies, continues to increase. It is estimated that factors such as stress, inadequate lifestyle, excessive consumption of processed, modified foods may contribute to this phenomenon.

The article presents the relationship between bacterial overgrowth in the small intestine and the effect on various aspects of food intolerances, both in the context of diagnosis and the course of these diseases on the basis of recent research. The nature of low FODMAP diet was presented, as well as its effect on the clinical course of small intestinal bacterial overgrowth and food intolerances.
\end{abstract}

Key words: SIBO, lactose intolerance, hydrogen breath test, FODMAP

\section{Introduction}

Food intolerances are increasingly common in the populations of developed countries. Disturbances in composition of bacterial flora of the human gastrointestinal tract is one of the important factors in the etiopathogenesis of this phenomenon. Microbiota undergoes modification under the influence of many factors, both external and internal.

A growing industry and an increasingly stressful lifestyle contribute to an increased incidence of gastrointestinal diseases as well as autoimmune diseases such as small intestinal bacterial overgrowth (SIBO) and food intolerances. These diseases may appear separately or coexist in an individual patient $[1,2]$. Incidence of food intolerances as well as allergies continues to increase. It is estimated that factors such as stress, inappropriate lifestyle or excessive consumption of processed, modified food may contribute to this [3]. It is assumed that food intolerances occur in about $20 \%$ of the world's population. There is a link between gastrointestinal or parenteral symptoms and food intolerances. Disturbance of microbiota composition in the intestines in course of SIBO may contribute to food intolerances [4].

The aim of the study is to present the current state of knowledge on the role of intestinal bacterial overgrowth in food intolerances.

\section{Small intestinal bacterial overgrowth}

Small intestinal bacterial overgrowth is characterized by increased fermentation of carbohydrates 
caused by an excessive amount of bacteria in the small intestine [5].

The typical clinical presentation of SIBO involves: abdominal pain, gases, flatulence, diarrhea or constipation [6]. Over $70 \%$ of the bacteria that live in the human body are found in the digestive tract. Microbiota plays an important role in modulating the body's homeostasis, influences the concentration of lipids, glucose, energy and vitamin production, and indirectly regulates the feeling of satiety. Normal microbiota has anti-inflammatory and anti-cancer properties, while abnormal microbiota has an influence on obesity and diabetes development, which has been proven in scientific research. Changes in composition of intestinal microflora may contribute to insulin resistance, functional disorders of the gastrointestinal tract, and also affect the development of intestinal inflammation [7].

The proximal jejunum and duodenum usually contain a small number of bacteria, mainly enterococci and lactobacilli, Gram-positive bacteria and facultative anaerobes. In healthy people, anaerobic bacteria are absent there, and are usually found in the large intestine. The distal part of the ileum is a transition zone between aerobic and anaerobic bacterial populations [8].

Bacteria in the large intestine can find their way into the distal ileum in excessive amounts, e.g., due to a malfunctioning ileocecal valve, after surgical interventions, or due to functional disorders. As a result, overgrowth of bacteria typical of the large intestine occurs in the small intestine $[9,10]$.

The presence of bacteria that feed on the host's macronutrients and micronutrients will result in less availability of nutrients absorbed from the digestive system. Moreover, SIBO may contribute to the damage of the intestinal villi, which in turn will result in carbohydrate malabsorption [11].

A correct diagnosis of SIBO is quite challenging. Moreover, the condition is sometimes resistant to treatment, even in patients who follow a specialized diet $[12,13]$. Hydrogen breathing tests remain the basic diagnostic method, a very minimally invasive method, but with limited sensitivity $[9,14]$.

\section{Food intolerances}

Food hypersensitivity can be categorized depending on the type of pathomechanism involved in its development. There is allergic hypersensitivity (confirmed or probable immune mechanism) and non-allergic hypersensitivity (immune mechanism excluded or not confirmed) [15].
The most common form of allergy is IgE-mediated allergic hypersensitivity. Among non-immunological hypersensitivity, a wide group of disorders of various etiology can be distinguished.

The first group of non-immune hypersensitivity involves enzyme-based intolerances. Enzymatic intolerances are reactions caused by absence of enzymes, which in turn result in malabsorption of e.g. carbohydrates. The lack of enzymes may be genetically determined or it may result from a gastrointestinal disease, that may lead to damage to the intestinal epithelium. Pharmacological intolerances are caused by chemicals in food, e.g., histamine, serotonin, caffeine. Severity of a patient's reaction depends on how the substance is metabolized in the body. Idiopathic intolerances belong to a wide group of adverse reactions, including toxic ones, caused e.g., by dyes, food preservatives or antioxidants. Some of these reactions may be based on immunological pathogenesis. Symptoms of food hypersensitivity due to psychogenic reactions are also possible. Sometimes the reaction that occurs in a patient is so unusual that it is necessary to make provocation tests to differentiate the etiology of symptoms $[16,17]$.

Intolerance of sugars, especially of lactose and fructose, is particularly worth paying attention, as they play a huge role in the pathogenesis of bacterial overgrowth in the small intestine.

Lactose intolerance is one of the most common problems in the general population. It is estimated that about $70 \%$ of adults suffer from lactose intolerance, which leads to reduced consumption of milk and dairy products in the daily diet. Intolerance (primary and secondary) can manifest itself at any age. Primary lactase deficiency is a lactose malabsorption syndrome associated with the physiological process of silencing the activity of the gene responsible for the production of lactase. Secondary lactase deficiency may occur in the course of various diseases of the intestinal mucosa, causing temporary impairment of lactase digestion. Lactose intolerance may appear as a result of diseases such as celiac disease, SIBO, viral or parasitic infections.

The human digestive tract is perfectly adapted to absorption of glucose, while fructose is absorbed less efficiently even in physiological conditions. In case of fructose intolerance, gastrointestinal symptoms such as abdominal pain, flatulence, nausea, diarrhea, and disturbed bowel movements are typical. Fructose intolerance occurs in two forms: as incomplete fructose absorption (otherwise known as fructose malabsorption syndrome) and as hereditary fructose intolerance (HFI). Fructose malabsorption is very often associated 
with irritable bowel syndrome. In both diseases, disturbances in the microbiota of the gastrointestinal tract are observed [18-20].

\section{Small intestinal bacterial overgrowth and food intolerances}

Bacterial overgrowth in the small intestine affects various aspects of food intolerance, both in terms of diagnosis and the course of these diseases.

Food intolerances may coexist with SIBO. In 2011, Yakoob et al. published an interesting study report involving retrospective analysis of 119 cases of patients with irritable bowel syndrome. It turned out that $19 \%$ of patients had SIBO, and $21 \%$ had lactose intolerance [21]. Zhao et al. used hydrogen breath tests with lactose and lactulose with simultaneous scintiscanning assessment of intestinal transit in patients with chronic functional diarrhea. The researchers found that bacterial overgrowth of the small intestine increased the risk of lactose intolerance in this group of patients, possibly as a result of lactose fermentation in the small intestine. This effect did not depend on the time of orocecal passage and visceral sensitivity of patients [22].

In 2015, Houben et al. published results of their retrospective study involving 1,051 people. The results of hydrogen breath tests with lactose were assessed. The diagnostic usefulness of the test and coexistence of other diseases with lactose intolerance were analyzed. Among the analyzed people, in 57\% lactose was properly digested, and $29.9 \%$ had lactose intolerance. Results obtained for $13.1 \%$ of patients suggested lactose malabsorption or SIBO. A high incidence of disturbances in the microbiota of the small intestine is noteworthy. It should be stressed that $41 \%$ of all subjects did not experience any side effects after taking lactose necessary for the breath test. Among people who complained about adverse effects associated with consumed lactose, 93\% reported gastrointestinal ailments. Symptoms were most often signaled by patients with impaired lactose tolerance associated with SIBO or lactose malabsorption syndrome. However, nearly half of the patients who tolerated lactose correctly also reported discomfort after consuming this sugar [23].

Varjú et al. carried out a retrospective analysis of 264 adult patients who underwent a hydrogen breath test using $50 \mathrm{~g}$ of lactose. Lactose digestion was diagnosed when the increase in $\mathrm{H}_{2}$ was $\geq 20$ ppm or the increase in blood glucose was less than $1.1 \mathrm{mmol} / 1$. Symptomatic patients meeting the above criteria were diagnosed with lactose intolerance. In case of patients with an early ( $\leq 90 \mathrm{~min})$ and significant $(\geq 20 \mathrm{ppm})$ increase in the concentration of $\mathrm{H}_{2}$ in the exhaled air, SIBO was suspected. In the analyzed group, $49.6 \%$ of patients had lactose digestion disorders, and 29.5\% had lactose intolerance. Interestingly, $34.8 \%$ of all patients and $60 \%$ of symptomatic patients were diagnosed with SIBO. The authors emphasize that SIBO often makes the diagnosis of lactose intolerance difficult due to false positive results of hydrogen breath tests. Detailed monitoring of the patient during the respiratory test, combined with the assessment of symptoms, may increase the sensitivity and specificity of the diagnosis of these diseases [24].

Silva et al. analyzed 117 medical students who responded to the invitation to participate in the study. Students were diagnosed using hydrogen breathing tests. Lactose intolerance was confirmed in eight patients $(6.8 \%)$ and SIBO in two (1.7\%). Lactose intolerance was more common in women than in men. Moreover, attention was drawn to the higher frequency of gastrointestinal symptoms in women than in men, which may be influenced by the menstrual cycle, and more frequent occurrence of gastrointestinal diseases in women [25].

350 subjects, including 175 healthy people and 175 patients with type 2 diabetes, participated in the study by Rana et al. All volunteers underwent fasting examination of bacterial overgrowth in the small intestine, after consuming $70 \mathrm{~g}$ of glucose dissolved in $250 \mathrm{ml}$ of water. Lactose intolerance was tested by a non-invasive hydrogen breath test with $25 \mathrm{~g}$ of lactose dissolved in $250 \mathrm{ml}$ of water. A significant incidence of lactose intolerance was observed in people with type 2 diabetes - in as much as $60 \%$ of subjects. In healthy subjects, the incidence of lactose intolerance was $39.4 \%$. It was noticed that in the study group, the bacterial overgrowth in the small intestine was more frequent than in the control group (14.8\% vs. $2.8 \%)$. On this basis, it was hypothesized that diabetes could contribute to the occurrence of food intolerances. Further research is required to verify this hypothesis [26].

Perets et al. performed a statistical analysis of the correlation between positive results for carbohydrate intolerance and bacterial overgrowth in the small intestine. 349 subjects were examined, including 231 women and 118 men, aged $53 \pm 19$ years. All patients underwent breathing tests as part of the diagnosis of gastrointestinal symptoms: abdominal distension and intestinal gas. It was found that in $81 \%$ of cases, people who tested positive for SIBO also were lactose intolerant. The same was true for sorbitol intolerance test. At the same time, when the test result for bacterial 
overgrowth was negative, a lower incidence of lactose and sorbitol intolerance was observed [27].

\section{Low FODMAP diet and elimination diet}

The FODMAP diet is based on exclusion of digestible, easily fermentable, short-chain carbohydrates from the diet. It is used in diseases such as SIBO and irritable bowel syndrome. With application of a proper diet under the supervision of a dietitian, digestive symptoms can often disappear completely. People with food intolerances also commonly suffer from SIBO. An appropriate diet is aimed at improving the quality of life of patients by reducing the severity of gastrointestinal symptoms.

In the case of lactose intolerance, excluding the sugar from the diet reduces occurrence of side effects. The FODMAP diet is based on the exclusion of products with a content of easily fermentable oligosaccharides, disaccharides, monosaccharides and polyols from the diet, thus supporting the treatment of food intolerance. Table 1 shows products containing high and low amounts of FODMAP, respectively.

Wilder-Smith et al. studied the effectiveness of the low FODMAP diet in patients with fructose and lactose intolerance. After applying the 6-8-week diet plan, $81 \%$ of patients experienced improved well-being and a reduced severity of symptoms. The type of intol- erance did not matter in this group. This study shows how an appropriate, special diet, tailored to a specific disease has a positive effect on minimizing symptoms in people struggling with various types of gastrointestinal disorders [28].

A total of 306 subjects participated in the study by Enko et al. $25.49 \%$ of them had primary lactose malabsorption syndrome. Fructose intolerance was diagnosed in $11.11 \%$ of examined patients, and in $18.63 \%$ sorbitol intolerance was found. It was found that bacterial overgrowth in the small intestine was associated with carbohydrate malabsorption. The diagnosis of small intestinal bacterial overgrowth was confirmed in $6.53 \%$ of people tested for carbohydrate intolerance. The patients were recommended a low FODMAP diet under the supervision of a dietician [29].

Hill et al. analyzed advantages, disadvantages and clinical aspects of the use of low FODMAP diets. They found that any elimination diet can lead to nutrient deficiencies, which in turn can have serious health consequences. The diet should be used under the supervision of a dietitian who pays attention to a balanced and healthy approach to a given diet, and who adapts the diet to individual needs of the patient. Low FODMAP or FODMAP diets should be used with caution. It is imperative to remember both the correct use of the phases of this diet and the reintroduction of restricted products at the right time [30].

Table 1. FODMAP content in selected products (based on [31]).

\begin{tabular}{|c|c|c|}
\hline FODMAP & High FODMAP products & Low FODMAP products \\
\hline $\begin{array}{l}\text { Oligosaccharides: fructans } \\
\text { and/or galactooligosaccharides }\end{array}$ & $\begin{array}{l}\text { Vegetables: artichokes, asparagus, beetroot, brussels } \\
\text { sprouts, broccoli, cabbage, garlic, leek, shallots, okra, } \\
\text { onion, peas }\end{array}$ & $\begin{array}{l}\text { Vegetables: carrots, cucumbers, potatoes, peppers, } \\
\text { eggplant, green beans, lettuce, spinach, chives, parsnips, } \\
\text { pumpkin, beetroot, chives (only green), tomato, zucchini, } \\
\text { bamboo shoots }\end{array}$ \\
\hline $\begin{array}{l}\text { Oligosaccharides: fructans } \\
\text { and/or galactooligosaccharides }\end{array}$ & $\begin{array}{l}\text { Cereals: wheat and rye eaten in large amounts (e.g., } \\
\text { bread, pasta, crackers) }\end{array}$ & $\begin{array}{l}\text { Cereals: grains without wheat or flour without wheat and } \\
\text { products made from them (e.g., bread, pasta, crackers), } \\
\text { spelled products, oats, corn, rice, quinoa }\end{array}$ \\
\hline $\begin{array}{l}\text { Oligosaccharides: fructans } \\
\text { and/or galactooligosaccharides }\end{array}$ & $\begin{array}{l}\text { Legumes: chickpeas, lentils, red beans, baked beans } \\
\text { Fruit: watermelon, cream apple, white peaches, } \\
\text { rambutan, kaki }\end{array}$ & Legumes: canned chickpeas \\
\hline Disaccharises: lactose & $\begin{array}{l}\text { Milk (cow, goat, sheep), yoghurt, soft and fresh chees- } \\
\text { es (e.g., ricotta), ice cream }\end{array}$ & $\begin{array}{l}\text { Lactose-free milk, rice milk, almond milk, lactose-free yo- } \\
\text { gurt, hard cheeses (e.g., cheddar, parmesan, Swiss cheese, } \\
\text { brie, camembert), butter, ice cream substitutes (e.g., non- } \\
\text {-dairy ice cream, sorbet) }\end{array}$ \\
\hline Monosaccharides: fructose & $\begin{array}{l}\text { Fruits: apples, pears, nashi pears, peaches, mangoes, } \\
\text { sugar snap peas, watermelon, canned fruit in natural } \\
\text { juice, dried fruit } \\
\text { Honey substitutes: maple syrup } \\
\text { Sweeteners: fructose, high fructose corn syrup }\end{array}$ & $\begin{array}{l}\text { Fruits: banana, blueberry, grapefruit, grape, honeydew mel- } \\
\text { on, kiwi, lemon, lime, mandarin, orange, tangelo, raspberry, } \\
\text { strawberry, passion fruit, watermelon, carambola, durian } \\
\text { Sweeteners: sugar, glucose, artificial sweeteners names of } \\
\text { which do not end in -ol }\end{array}$ \\
\hline Polyols & $\begin{array}{l}\text { Fruits: apples, apricots, cherries, lychees, nashi pears, } \\
\text { nectarines, pears, peaches, plums, watermelon } \\
\text { Vegetables: avocado, cauliflower, mushrooms } \\
\text { Sweeteners: sorbitol, mannitol, xylitol and others with } \\
\text { names ending in -ol, isomalt }\end{array}$ & $\begin{array}{l}\text { Fruits: banana, blueberry, grapefruit, grape, kiwi, lemon, } \\
\text { lime, mandarin, orange, raspberry, passion fruit, water- } \\
\text { melon } \\
\text { Sweeteners: sugar, glucose, artificial sweeteners names of } \\
\text { which do not end with -ol (e.g., aspartame) }\end{array}$ \\
\hline
\end{tabular}




\section{Conclusions}

Small intestinal bacterial overgrowth often occurs simultaneously with food intolerances. Coexistence of these conditions may exacerbate their symptoms. At the same time, it is worth paying attention to the fact that the diagnosis of SIBO is not always easy, and incorrect interpretation of the breath test result may prevent a correct diagnosis. Choosing the right diet for the patient, taking into account their ailments, food intolerances and tolerances as well as taste preferences, allows for a significant reduction in severity of symptoms and improvement in the quality of life.

\section{References}

1. Savage J, Johns CB. Food allergy: epidemiology and natural history. Immunol Allergy Clin. 2015; 35(1): 45-59.

2. Ruscio M. Is SIBO A Real Condition? Altern Ther Health Med. 2019; 25(5): 30-8.

3. Crowe SE. Food allergy vs food intolerance in patients with irritable bowel syndrome. Gastroenterol Hepatol. 2019; 15(1): 38.

4. Tuck CJ, Biesiekierski JR, Schmid-Grendelmeier P et al. Food intolerances. Nutrients. 2019; 11(7): 1684.

5. Esposito S, Biscarini A, Federici B et al. Role of Small Intestinal Bacterial Overgrowth (SIBO) and Inflammation in Obese Children. Front Pediatr. 2020; 8: 369.

6. Pawlak K, Rudzik R, Lewiński $M$ et al. Dieta L-FODMAP $w$ leczeniu zespolu jelita drażliwego. Bromat Chem Toksykol. 2017; 2: 179-83.

7. Olszewska J, Jagusztyn-Krynicka EK. Human Microbiome Project - mikroflora jelit oraz jej wptyw na fizjologię i zdrowie człowieka. Post Mikrobiol. 2012; 51(4): 243-56.

8. Ghoshal UC, Shukla R, Ghoshal U. Small intestinal bacterial overgrowth and irritable bowel syndrome: a bridge between functional organic dichotomy. Gut Liver. 2017; 11(2): 196.

9. Paik CN, Choi MG, Lim CH et al. The role of small intestinal bacterial overgrowth in postgastrectomy patients. Neurogastroenterol Motil. 2011; 23(5): e191-6.

10. Avelar Rodriguez D, Ryan PM, Toro Monjaraz EM et al. Small intestinal bacterial overgrowth in children: a state-of-the-art review. Front Pediatr. 2019; 7: 363.

11. Adike A, DiBaise JK. Small intestinal bacterial overgrowth: nutritional implications, diagnosis, and management. Gastroenterol Clin. 2018; 47(1): 193-208.

12. Tordesillas L, Berin MC, Sampson HA. Immunology of food allergy. Immunity. 2017; 47(1): 32-50.

13. Mądry E, Krasińska B, Walkowiak J. Hipolaktazja, zespót złego wchłaniania laktozy, nietolerancja laktozy. Fam Med Prim Care Rev. 2011; 2: 334-6.
14. Braden B. Methods and functions: Breath tests. Best Pract Res Clin Gastroenterol. 2009; 23(3): 337-52.

15. Bartuzi Z, Ukleja-Sokołowska N. Alergia pokarmowa na mąkę i celiakia. Alergia. 2014; 2: 4-10.

16. Ukleja-Sokołowska N, Zacniewski R, Gawrońska-Ukleja E et al. Food-dependent, exercise-induced anaphylaxis in a patient allergic to peach. Int J Immunopathol Pharmacol. 2018; 32: 2058738418803154

17. Szilagyi A, Ishayek N. Lactose intolerance, dairy avoidance, and treatment options. Nutrients. 2018; 10(12): 1994.

18. Coffee EM, Tolan DR. Mutations in the promoter region of the aldolase B gene that cause hereditary fructose intolerance. J Inherit Metab Dis. 2010; 33(6): 715-25.

19. Żelowski A, Wojtuń S, Gil J et al. Zespót jelita nadwrażliwego - podstawowe zasady rozpoznawania i leczenia. Pediatria i Medycyna Rodzinna. 2013; 9(3): 250-5.

20. Mehta M, Beg M. Fructose intolerance: cause or cure of chronic functional constipation. Glob Pediatr Health. 2018; 5: $2333794 X 18761460$.

21. Yakoob J, Abbas Z, Khan R et al. Small intestinal bacterial overgrowth and lactose intolerance contribute to irritable bowel syndrome symptomatology in Pakistan. Saudi J Gastroenterol. 2011; 17(6): 371.

22. Zhao J, Fox M, Cong Y et al. Lactose intolerance in patients with chronic functional diarrhoea: the role of small intestinal bacterial overgrowth. Aliment Pharmacol Ther. 2010; 31(8): 892-900.

23. Houben E, De Preter V, Billen J et al. Additional value of CH4 measurement in a combined $13 \mathrm{C} / \mathrm{H} 2$ lactose malabsorption breath test: a retrospective analysis. Nutrients. 2015; 7(9): 7469-85.

24. Varjú P, Ystad B, Gede $N$ et al. The role of small intestinal bacterial overgrowth and false positive diagnosis of lactose intolerance in southwest Hungary - A retrospective observational study. PloS ONE. 2020; 15(5): e0230784.

25. Silva CD, Leite ID, Rodrigues JW et al. Analysis of lactose intolerance in students with suggestive symptoms of irritable bowel syndrome. Arq Gastroenterol. 2019; 56(3): 304-11.

26. Rana SV, Malik A, Bhadada SK et al. Malabsorption, orocecal transit time and small intestinal bacterial overgrowth in type 2 diabetic patients: a connection. Indian J Clin Biochem. 2017; 32(1): 84-9.

27. Perets TT, Hamouda D, Layfer O et al. Small intestinal bacterial overgrowth may increase the likelihood of lactose and sorbitol but not fructose intolerance false positive diagnosis. Ann Clin Lab Sci. 2017; 47(4): 447-51.

28. Wilder-Smith CH, Olesen SS, Materna A et al. Predictors of response to a low-FODMAP diet in patients with functional gastrointestinal disorders and lactose or fructose intolerance. Aliment Pharmacol Ther. 2017; 45(8): 1094-106.

29. Enko D, Kriegshäuser G, Kimbacher $C$ et al. Carbohydrate malabsorption and putative carbohydrate-specific small 
intestinal bacterial overgrowth: prevalence and diagnostic overlap observed in an Austrian outpatient center. Digestion. 2015; 92(1): 32-8.

30. Hill P, Muir JG, Gibson PR. Controversies and recent developments of the low-FODMAP diet. Gastroenterol. Hepatol. 2017; 13(1): 36-45.

31. Cozma-Petrut A, Loghin F, Miere D et al. Diet in irritable bowel syndrome: What to recommend, not what to forbid to patients! World J Gastroenterol. 2017; 23(21): 3771-83.

ORCID

M. Bartuzi - ID - http://orcid.org/0000-0003-1988-8348

N. Ukleja-Sokołowska - ID - http://orcid.org/0000-0001-5957-8382

Authors' contributions:

M. Bartuzi: 80\%; N. Ukleja-Sokołowska: 20\%.

Conflict of interests:

The authors declare that they have no competing interests.

Financial support:
Does not occur.

Ethics:

The contents presented in this paper are compatible with the rules the Declaration

of Helsinki, EU directives and standardized requirements for medical journals.

Copyright: () Medical Education sp. z 0.0. This is an Open Access article distributed under the terms of the Attribution-NonCommercial 4.0 International (CC BY-NC 4.0). License (https://creativecommons.org/licenses/by-nc/4.0/), allowing third parties to copy and redistribute the material in any medium or format and to remix, transform, and build upon the material, provided the original work is properly cited and states its license.

\section{Correspondence}

\section{Natalia Ukleja-Sokołowska, MD, PhD}

Department of Allergology, Clinical Immunology and Internal Diseases, Collegium Medicum in Bydgoszcz, Nicolaus Copernicus University in Toruń 85-168 Bydgoszcz, Ujejskiego 75 e-mail: ukleja@10g.pl tel. 691973969 